\title{
Co-treatment of industrial air streams using A.O.P. and adsorption processes
}

\author{
P. Monneyron, ${ }^{2}$ A. De La Guardia, ${ }^{1}$ M. H. Manero, ${ }^{2}$ E. Oliveros, ${ }^{3}$ \\ M. T. Maurette, ${ }^{1}$ and F. Benoit-Marquié ${ }^{1}$ \\ ${ }^{1}$ Laboratoire des IMRCP, UMR 5623, Université Paul Sabatier, 118 rte de Narbonne, 31062 Toulouse cedex 4, France \\ ${ }^{2}$ LIPE, Département GPI, Institut National des Sciences Appliquées, 135 av de Rangueil, 31077 Toulouse, France \\ ${ }^{3}$ Lehrstuhl für Umweltmesstechnik, Engler-Bunte-Institut, Universität Karlsruhe, 7500 Karlsruhe, Germany
}

\begin{abstract}
Coupling adsorption with two different photochemical oxidation methods was investigated, in order to treat industrial gaseous effluents containing a low concentration of Volatile Organic Compounds (VOC). Prior to adsorption/photocatalysis cyclic study, new $\mathrm{TiO}_{2}$ based catalysts were prepared by impregnating commercial zeolites in pellets form using a sol-gel technique. Scanning Electronic Microscopy observations linked to BET and adsorption equilibrium measurements of two VOC (1-butanol or BuOH and methyl-ethyl-ketone or MEK) showed that $\mathrm{TiO}_{2}$ happened to fix on the inert binder, without significant modification of support properties. A specific diffusion cell was used to produce dilute polluted air streams for each VOC in dynamic experiments, in which adsorption and photodegradation phases were alternatively carried out. Adsorption/photocatalysis co-treatment unable the total degradation of $\mathrm{BuOH}$, and the regeneration of adsorbent. When using V-UV photolysis, pure zeolites were used, irradiated at $172 \mathrm{~nm}$ with an xenon excimer lamp. Excellent results were observed, since a total and rapid degradation was obtained for both VOC, especially thanks to a determining role of ozone.
\end{abstract}

\section{INTRODUCTION}

Volatile Organic Compounds (VOC) are major air pollutants coming largely from industrial processes. Thus, purification of effluents is of great necessity, and one of the main technique available towards dilute polluted airstreams is adsorption onto a porous material. This process is usually conducted in two-steps, since the saturated material requires regeneration [1].

During the last decade, developments in the area of chemical water and air treatment have led to an improvement of organic pollutants oxidative techniques, in particular when using photochemical methods. They are generally referred to as Advanced Oxidation Processes (AOP). Bearing in mind the industrial applications objectives, researchers have focused their work on design and development of new light sources and photochemical reactors, but also on the preparation of efficient photocatalysts. AOP are entirely based upon oxidative degradation reactions, in which organic radicals are generated through photolysis of the organic substrate or consecutively to a reaction with hydroxyl and/or oxygen radicals [2]. In this study, the combination of adsorption with two different photooxidation methods was investigated. They are photocatalysis and V-UV photolysis.

Photocatalysis of air pollutants has been largely developed using the classical UV-sensible catalyst, titanium dioxide $\left(\mathrm{TiO}_{2}\right)$ [3]. However, since $\mathrm{TiO}_{2}$ is mainly produced in powder form, which is technologically impracticable in continuous engineering processes, many attempts have been made to prepare supported catalysts, using fibber glass [4], stainless steel [5], fibber textile [6], quartz beads [7], honeycomb [8], activated carbon [9], and zeolites [10]. Besides a large adsorption capacity, High Silica Zeolites (HSZ) exhibit notably a very low dependence on effluent humidity, contrary to activated carbon [11], and on compound's polarity, which may be of particular interest since nonpolar molecules hardly adsorb on pure $\mathrm{TiO}_{2}$ [12]. In order to develop enhanced photoactivity of titanium dioxide, investigators elaborated very different methods to support active titanium on zeolites, from simple amalgam of powders through mechanical mixing [13] or with papermaking techniques [14], to chemical vapour deposition [15], cation exchange [16], or direct synthesis [17] which tend to create $\mathrm{Ti}-\mathrm{O}$ - Si bonds. In this study, zeolite based catalysts were prepared using a sol-gel method, and specific behaviour of adsorption and photocatalysis of daily used industrial solvents, 1butanol (BuOH) and 2-butanone, known as methyl ethyl ketone (MEK), were determined.

V-UV photolysis is the vacuum ultra-violet irradiation of pollutants [18]. This method is very efficient for water treatment [19] since it leads to water molecules photolysis and therefore to an important hydroxyl radicals production. Until now, it was scarcely used for gaseous stream treatment [20], and never used for adsorbent regeneration.

\section{EXPERIMENTAL}

2.1. Chemicals and zeolites supports. Titanium (IV) butoxide (99\%), 2,4-pentanedione (99\%), 1-butanol 
Table 1. Main properties of adsorbents.

\begin{tabular}{lccc}
\hline Symbol & Crystalline type (Pore structure) & Si $/$ Al ratio & Available porous volume $\left(\mathrm{cm}^{3} \cdot \mathrm{g}^{-1}\right)$ \\
\hline DAY & Faujasite Y $(\alpha$-cage $)$ & $>100$ & 0.30 \\
DAZ & ZSM-5 (interconnected channels) & $>500$ & 0.19 \\
\hline
\end{tabular}

(99.5\%), and 2-butanone (99.5\%) were all purchased from Aldrich, and used without further purification. Absolute ethanol came from ACS for Analysis, RPE, Carlo Erba. The commercial zeolites used in this study were cylindrical pellets (diameter $2 \mathrm{~mm}$, length $5 \mathrm{~mm}$ ) supplied by Degussa. The granular solids were made of microcrystals of zeolites arranged together with a clay binder (20\% weight). Table 1 summarises the adsorbent main properties.

\subsection{Preparation of supported titanium dioxide} catalysts [21]. The catalysts were prepared by impregnation of supports with a $\mathrm{TiO}_{2}$ Sol-Gel. The synthesis method is summarised here. 0.1 mole of titanium (IV) butoxide was dissolved in 1 mole of absolute ethanol in an argon atmosphere and refluxed for 12 hours. 0.05 mole of 2,4-pentanedione and 0.01 mole of double distilled water were added dropwise under vigorous stirring. After refluxing for several hours, the clear solution was concentrated by solvent distillation. An amorphous and translucid gel was obtained. It contains enough alcohol to avoid ageing and could therefore be stored unchanged for several weeks. The $\mathrm{TiO}_{2}$ coating was made by completely immersing the different supports in the gel. The wet materials could then undergo a two steps hot air treatment. In the first stage the catalyst system was dried at $100^{\circ} \mathrm{C}$, whereas in the second part the desired crystalline anatase phase was obtained at $450{ }^{\circ} \mathrm{C}$. The synthesised catalyst are referred to as DAY* and DAZ*, respectively for DAY and DAZ based solids.

2.3. Characterisation of catalysts. Elemental analysis was performed by the analysis central center of the Centre National de la Recherche Scientifique (CNRS) using flame emission spectrometry. The specific surface area and porous distribution of adsorbents were determined using argon adsorption-desorption experiments at $77 \mathrm{~K}$, using a conventional BET adsorption apparatus (ASAP 2010, Micrometrics). Degassing of samples was performed at $120^{\circ} \mathrm{C}$ overnight. This equipment allowed the description of both microporosity (pore size smaller than $2 \mathrm{~nm}$ ) and mesoporosity (between 2 and $50 \mathrm{~nm}$ ). A scanning electron microscopy (JSM-840 A, JEOL) was operated at $20 \mathrm{keV}$, providing information on local properties together with chemical composition of material activated by electronic bombardment (EDS facility). Prior to analysis, the granulates were coated with gold to ensure conductivity. Both external and cross-section surfaces of samples were analysed. In order to characterise the influence of impregnation on adsorption capacities of zeolites, batch adsorption isotherms were performed using a volumetric method [22].

2.4. Gas phase adsorption/photodegradation experiments. The polluted air stream used in dynamic photodegradation experiments was generated with a diffusion cell [23], which can produce dilute gas mixtures accurately for very long period of time. The diffusion rate initially expressed by the Altshuller \& $\mathrm{Co}^{-}$ hen equation was used in a previous study [24] for the prediction of the experimental temperature dependent relation, using Antoine equation to estimate the vapour pressure of liquid, and Fuller relation for diffusion coefficient calculation. Here, a 80 : $20 \mathrm{~N}_{2} / \mathrm{O}_{2}$ mixture, supplied by Air Liquide, continuously flushed the mixing reservoir, regulated by a mass flowmeter (Brooks 58505, 10-50 $\mathrm{mL} \cdot \mathrm{min}^{-1}$ ), leading to a VOC concentration ranging between 300 and $5000 \mathrm{mg} \cdot \mathrm{m}^{-3}$, thermally controlled. Both adsorption and irradiation phases were carried out in a continuous flow multilamp annular reactor (length: $15 \mathrm{~cm}$, optical path length: $3 \mathrm{~mm}$, total volume: $60 \mathrm{~cm}^{3}$ ) shifting from adsorption to oxidation phase just by turning the lamp on once breakthrough curve was totally described and adsorbent saturation completed. The VOC inlet concentration was kept unchanged during irradiation, which was interrupted as soon as the outlet concentration of VOC and by-products became still. This choice lead one to analyse final adsorption/photochemical steady-state instead of complete regeneration time which may be uneasy to characterise considering the complex mechanisms involved in this process. Efficiency of degradation was then estimated in terms of outlet to inlet concentration ratio. For photocatalytic experiments, a medium pressure mercury arc (Phillips HPK $125 \mathrm{~W}$, photonic rate: $6.2 \times 10^{18}$ photon $\cdot \mathrm{s}^{-1}$ [25]) was positioned in the internal cylinder, entirely made of Pyrex to avoid photolysis of compounds, and cooled with an air stream. For V-UV photolysis experiments, an quasimonochromatic $172 \mathrm{~nm}$ Xenon excimer lamp was used (photonic rate: $8.3( \pm 0.5) \times 10^{18}$ photons $\cdot \mathrm{s}^{-1}[26]$ ), as shown in Figure 1 . The fixed bed of catalysts was supported by means of a non porous quartz cloth inserted in the annular space and, with a typical mass of $2 \mathrm{~g}$, an homogeneous bed height of about $1 \mathrm{~cm}$ was obtained. The on-line reactor outlet analysis was performed using a Chrompack CP900 gas chromatograph, and a PerkinElmer 1760-x Infra Red spectrograph equipped with a DTGS detector for $\mathrm{CO}_{2}, \mathrm{O}_{3}$ and $\mathrm{H}_{2} \mathrm{O}$ detection. In IR analysis, the gas sample continuously flushed a $90 \mathrm{~mL}$ $\mathrm{NaCl}$ cell. 


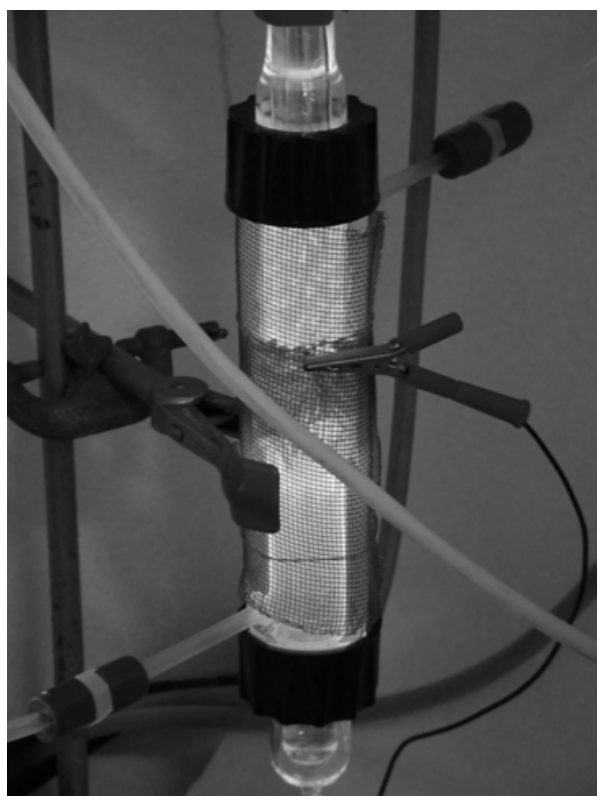

Figure 1. Annular reactor during V-UV photolysis experiments.

\section{ADSORPTION/PHOTOCATALYSIS RESULTS}

3.1. Characterisation of $\mathrm{TiO}_{2}$-Zeolites catalysts. The reproducibility of impregnation was checked by evaluating the gain of mass from $\mathrm{TiO}_{2}$ coating through a simple and rapid weighting method. The $\mathrm{TiO}_{2}$ mass content of DAY* and DAZ* was $15 \% \pm 1 \%$, confirmed by elemental quantification, with a titanium content of $9 \%$ for $\mathrm{DAY}^{*}$ and $10 \%$ for DAZ* . X-Ray analysis have clearly demonstrated that the $\mathrm{TiO}_{2}$ deposited on zeolites was totally in the anatase crystalline form [27].

Intimacy and homogeneity of $\mathrm{TiO}_{2}$ loading-SEMEDS analysis. Results of external and cross-section surfaces of samples where very similar in terms of mixing and titanium content, determined through $\mathrm{Si} / \mathrm{Ti}$ ratio calculations. Figure 2 shows SEM pictures of crosssection surfaces for the two catalysts.

On the DAZ* sample, the zeolites crystallites can be easily isolated via their rectangular shape. Using the microprobe elemental analysis (EDS), no titanium was detected on the zeolites crystals whereas a high content of titanium was found in the clearer irregular parts, mixing $\mathrm{TiO}_{2}$ microcrystals and binder. The $\mathrm{DAY}^{*}$ structure is quite different from DAZ*. The zeolites crystals are much smaller and they could not be distinguished from binder or $\mathrm{TiO}_{2}$, showing a greater intimacy of loading during sol-gel method. Homogeneity of catalysts was found to be fairly satisfactory, and strongly determined by the initial material, and zeolite crystals size.

Specific surface area modification-BET analysis. BET adsorption isotherms on the different samples were all of type Ia of IUPAC classification [28],
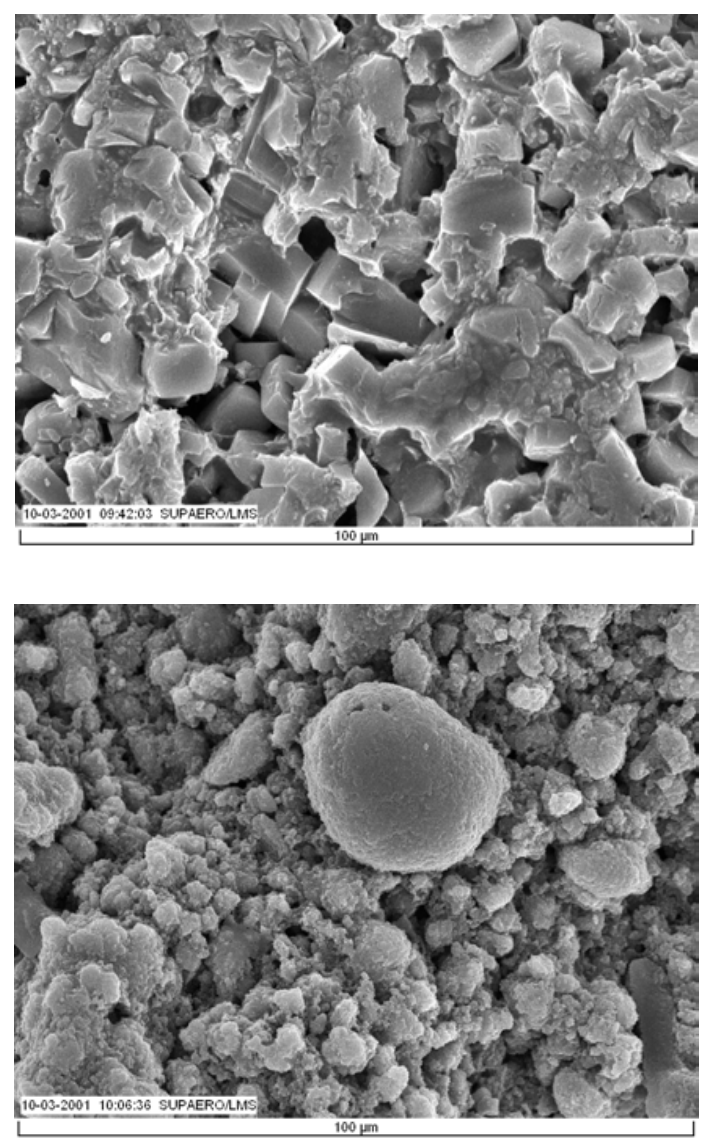

Figure 2. SEM pictures $(\mathrm{G}=1200)$ of internal surface. $\mathrm{DAZ}^{*}$ (top), DAY* (bottom).

corresponding to a microporous adsorbent with a small hysteresis coming from multilayer adsorption/desorption in mesopores. Microporous distribution was checked using Horvath-Kawazoe model extended by Saïto \& Foley for a cylindrical pore geometry. Structure of zeolites were confirmed, with a monomodal porous distribution for faujasite $\mathrm{Y}$, at $13.8 \AA$ and bimodal for ZSM-5, at 10.0 and $12.6 \AA$. The modification of support's surface due to $\mathrm{TiO}_{2}$ loading was investigated by two means. First, the surface area of catalysts where determined with Langmuir approach as shown in Table 2. This model was preferred to BET or Dubinin-Radushkevich equation considering the monomolecular adsorption taking place in microporous adsorbent.

The very good agreement between experimental and calculated surface areas confirm that $\mathrm{TiO}_{2}$ loading does not have a strong impact on support's physical properties. The $B J H$ model was applied to hysteresis parts of adsorption isotherms, indicating that on both adsorbents, the $\mathrm{TiO}_{2}$ coating developed a noticeable mesoporous volume. These observations stand promising for photocatalytic experiments, mesopores being predominant sites for photocatalysis. 
Table 2. Specific surface area of catalysts.

\begin{tabular}{|c|c|c|c|}
\hline Adsorbent & $\begin{array}{l}\text { Specific surface area of } \\
\text { adsorbent }^{(a)}\left(\mathrm{m}^{2} / \mathrm{g}\right)\end{array}$ & $\begin{array}{c}\text { Specific surface area of } \\
\mathrm{TiO}_{2} \text {-loaded adsorbent }{ }^{(\mathrm{b})}\left(\mathrm{m}^{2} / \mathrm{g}\right)\end{array}$ & $\begin{array}{c}\text { Calculated surface area of } \\
\text { mixture }^{(\mathrm{c})}\left(\mathrm{m}^{2} / \mathrm{g}\right)\end{array}$ \\
\hline $\operatorname{SGP}^{(d)}$ & 65 & & \\
\hline DAY & 645 & 568 & 566 \\
\hline DAZ & 379 & 337 & 336 \\
\hline
\end{tabular}

(a) Zeolites adsorbent have a binder mass content of $20 \%$.

(b) The composition of catalysts is zeolite-binder- $\mathrm{TiO}_{2}(69: 16: 15)$.

(c) The calculated value of surface area was done considering that the surface area of adsorbent came only from zeolites crystals, and consequently, by normalizing the surface areas with the zeolite mass content. Expression of calculation is then: $\left[\mathrm{S}_{\mathrm{Calc}}=\left(\mathrm{S}_{\mathrm{Ads}} / 0.80\right) \times 0.69+\mathrm{S}_{\mathrm{SGP}} \times 0.15\right]$.

(b) Sol gel powder.
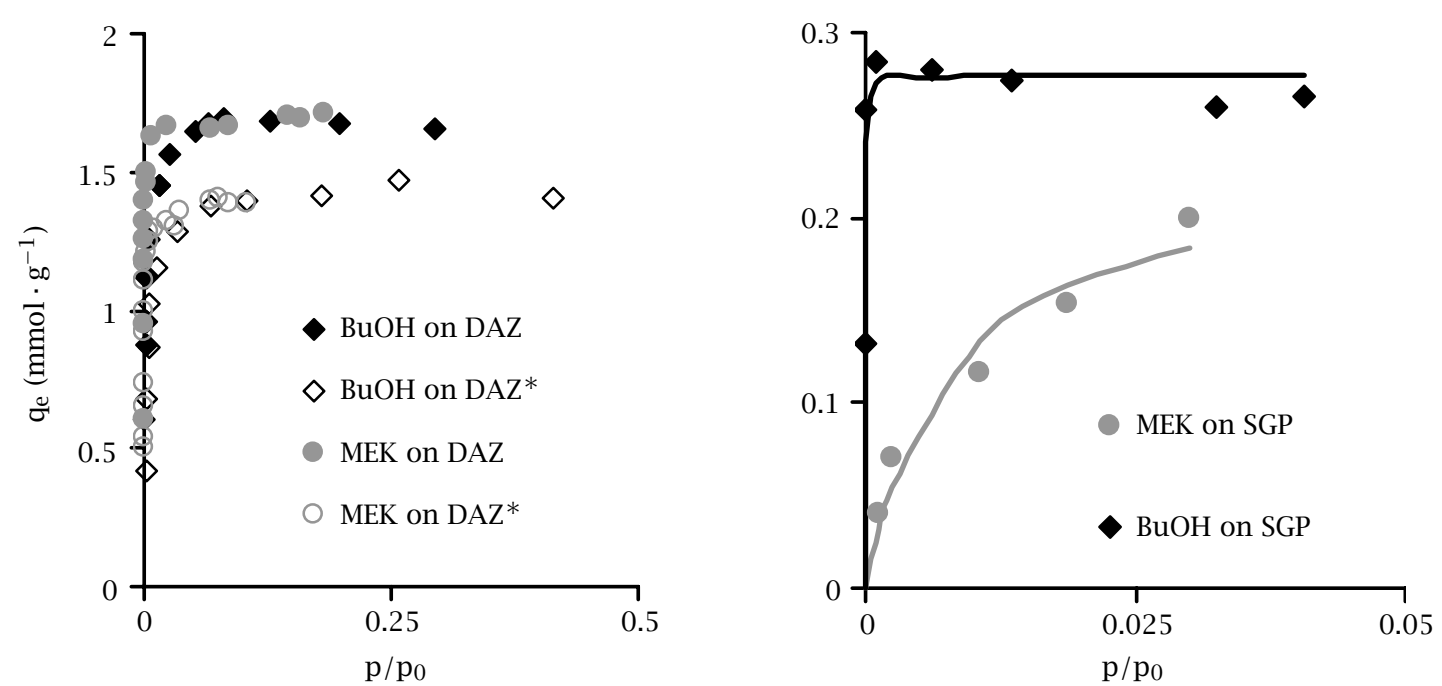

Figure 3. Single component adsorption isotherms, on $\mathrm{DAZ}^{(*)}$ adsorbents (left), on SGP (right).

VOC adsorption properties of catalysts-Volumetric batch experiments. Single component adsorption isotherms of $\mathrm{BuOH}$ and MEK were carried out on naked and coated adsorbents. Representative results are given in Figure 3, $\mathrm{p}_{0}$ being vapour pressure of VOC.

For the two VOC used in this study, no steric effect happened, and both compounds had very similar adsorption mechanisms. As can be seen on the left part of Figure 3, the maximum adsorption capacity was reduced by $\mathrm{TiO}_{2}$ loading, and was then directly proportional to the available pore volume of zeolites given in Table 1. Similar results where found for DAY* materials, demonstrating that VOC adsorption on synthesised catalysts was almost completely driven by the properties of zeolite, whose micropores remained totally unobstructed by $\mathrm{TiO}_{2}$ loading, contrary to the BET results obtained by Hsien, et al. [29] when impregnating zeolite powders. As shown in the right part of Figure 3, adsorption mechanism of both VOCs on $\mathrm{TiO}_{2}$ anatase was also clarified thanks to this experimental technique. Very different behaviour were observed and quantified using Langmuir model. VOC adsorption maximum capacities (Qmax) given by the model were quite close in favour to $\mathrm{BuOH}$, respectively $0.28 \mathrm{mmol} \cdot \mathrm{g}^{-1}$ for $\mathrm{BuOH}$ and
$0.23 \mathrm{mmol} \cdot \mathrm{g}^{-1}$ for MEK, but adsorption energy parameter $(b)$ differed largely: $1.3 \times 10^{2}$ for $\mathrm{BuOH}$ and $6.9 \times 10^{4}$ for MEK, pointing at the great affinity between $\mathrm{TiO}_{2}$ and hydroxyl functional groups. It is interesting to note that, dealing with $Q \max$, similar tendencies between alcohols and ketones was found by Alberici [30] but with values being half of the ones found here, whereas same order values were obtained by Raupp [31].

\subsection{Cyclic adsorption/photocatalytic oxidation} dynamic experiments. Figure 4 presents the outlet concentration of the reactor versus time during the cyclic study of adsorption breakthrough curves (A) followed by photocatalytic phase $(\mathrm{P})$ of $\mathrm{BuOH}$ on $\mathrm{DAY}^{*}$ for an inlet concentration of $550 \mathrm{mg} \cdot \mathrm{m}^{-3}$.

Several preliminary remarks are to be made. Due to a great temperature dependence of the adsorption mechanism, fluctuations can be observed in each of the three adsorption periods, coming from laboratory temperature change during night and day, of about $\pm 2{ }^{\circ} \mathrm{C}$. In the same way, a thermodesorption was observed when initialising irradiation phase. Photocatalysis lead to significant degradation of $\mathrm{BuOH}$, consecutively 94 and 93\%. Regeneration of adsorption 


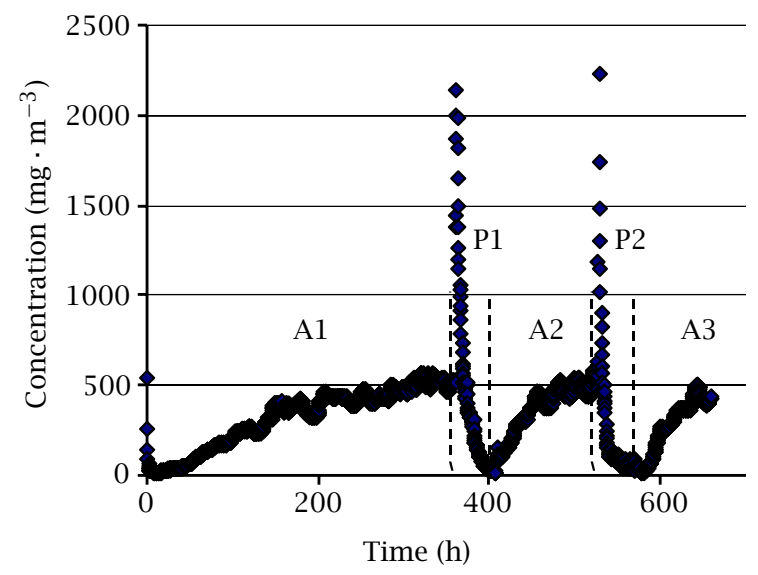

Figure 4. Cyclic study of adsorption/photodegradation of $\mathrm{BuOH}$ on $\mathrm{DAY}^{*}$.

capacity was estimated by comparing the saturation time of adsorbent before and after the irradiation. In both cases, a partial regeneration was found of about $30 \%$. This value is totally dependent on the experimental conditions (experimental set up design, irradiation conditions, inlet concentration and flow) but also on the competitive mechanisms of photochemical reactions, adsorption and desorption of VOC. Still, this value remaining constant indicates that no poisoning of catalysts occurred when irradiated. The concentration of $\mathrm{BuOH}$ oxidation sub-products (C2 to $\mathrm{C} 4$ alcohols and corresponding aldehydes and butanoic acid) was also determined in the outlet, after individual identification through direct injection of chemical's vapour. The evolutions of their respective concentration were very close to those obtained in a previous study on loaded silica beads in similar conditions by Benoit-Marquié, et al. [25], the aldehydes outlet concentration being greater than the corresponding alcohol. This could be directly attributed to the greater affinity of $\mathrm{TiO}_{2}$ toward alcohols mentioned in the single component adsorption isotherms paragraph, that can lead to a selective $\mathrm{TiO}_{2}$-adsorption, and therefore a selective degradation, when dealing with the dynamic mixture. These findings tend to indicate that the zeolite used in this study does not interfere with the oxidative mechanisms that occur on the active $\mathrm{TiO}_{2} \mathrm{UV}$-sensible sites; the unloaded zeolites had no catalytic properties when irradiated in identical conditions. Supporting $\mathrm{TiO}_{2}$ on zeolites may have two different impacts on photocatalysis reactions: firstly it is clear that by creating a high concentration of compounds around $\mathrm{TiO}_{2}$ sites, kinetic rates are to increase significantly. This phenomenon was observed in batch experiments by many researchers [32, 33]. Secondly, the zeolites, being acid material, may influence selectivity of reactions through chemisorption on Lewis or Brönsted strong acid sites, induced by aluminium atoms [34]. Here, the impact of acidity on oxidation rate remains unclear since the zeolites used here had a very high $\mathrm{Si} / \mathrm{Al}$ ratio, but it may tend to reduce mass transfer between external adsorption sites, and $\mathrm{TiO}_{2}$ sites. The same study was performed with a $\mathrm{BuOH}$ inlet concentration of $2000 \mathrm{mg} \cdot \mathrm{m}^{-3}$, leading to similar sub-products curves, but to a different degradation steady state of $75 \%$, which can be easily explained by the competitive adsorption and photodegradation mechanisms. Finally, the DAZ* catalyst was studied with a $2000 \mathrm{mg} \cdot \mathrm{m}^{-3}$ inlet concentration: irradiation lead very rapidly to a steady state of $40 \%$ of degradation, but only a very small adsorbent regeneration was obtained (about 5\%).

In this study, two main parameters are distinguishing $\mathrm{DAY}^{*}$ and $\mathrm{DAZ}^{*}$ catalysts that can explain the differences observed in photocatalysis experiments. Firstly, it is obvious that the zeolite framework structure has a decisive impact, intracristalline diffusion being faster in faujasite Y than in ZSM-5. Secondly, SEM measurements showed that DAY crystals were smaller than DAZ ones, creating a greater intimacy of mixing and a larger mesoporous volume. Therefore, zeolite crystals size is likely to limit mass transfer in the catalyst. It was not possible to determine here their respective influence, but in both cases, intracristalline diffusion is the microscopic decisive parameter. These dynamic results confirm the work of Yoneyama and coworkers [35] who pointed at the major influence of diffusion in adsorbent used as a support for $\mathrm{TiO}_{2}$ by studying the effects of adsorption strength of adsorbent supports on the rate of photodegradation.

Preliminary experiments with MEK were carried out on $\mathrm{DAY}^{*}$ catalyst using a $1700 \mathrm{mg} \cdot \mathrm{m}^{-3}$ inlet concentration. Irradiation lead very rapidly to a steady-state of only $5 \%$ of degradation, and logically no adsorbent regeneration was obtained. When comparing photocatalytic experiments towards MEK and $\mathrm{BuOH}$, it is clear that their differentiating chemical functional groups play a determining role. Since in single component adsorption experiments, comparable behaviour were obtained for both VOC on zeolites, the greatly different affinities toward pure $\mathrm{TiO}_{2}$ powder (SGP) noticed is to explain the larger conversion of $\mathrm{BuOH}$. Keller-Spitzer [36] obtained a similar poor MEK degradation using a thin $\mathrm{TiO}_{2}$ film, but reached a much higher conversion efficiency when doping the $\mathrm{TiO}_{2}$, likely by inducing a greater adsorption energy.

\section{ADSORPTION/V-UV PHOTOLYSIS RESULTS}

The degradation of several VOC $(\mathrm{BuOH}, 1$-butylamine, benzene, toluene, and phenol) using V-UV photolysis has been studied in the last few years in our laboratory $[18,24]$. This method lead to total mineralization of compounds whatever flow and concentration were chosen up to a concentration of $5000 \mathrm{mg} \cdot \mathrm{m}^{-3}$. No organic compounds were detected in gas phase 
chromatography analysis, and IR spectrometry was used to look at mineralization products $\left(\mathrm{H}_{2} \mathrm{O}\right.$ and $\left.\mathrm{CO}_{2}\right)$ and at the ozone formed by air oxygen photolysis. Here, co-treatment by adsorption and photolysis V-UV was studied using zeolite as a pollutant reservoir, bearing in mind that zeolite would stand as an obstacle to photonmolecule contact.

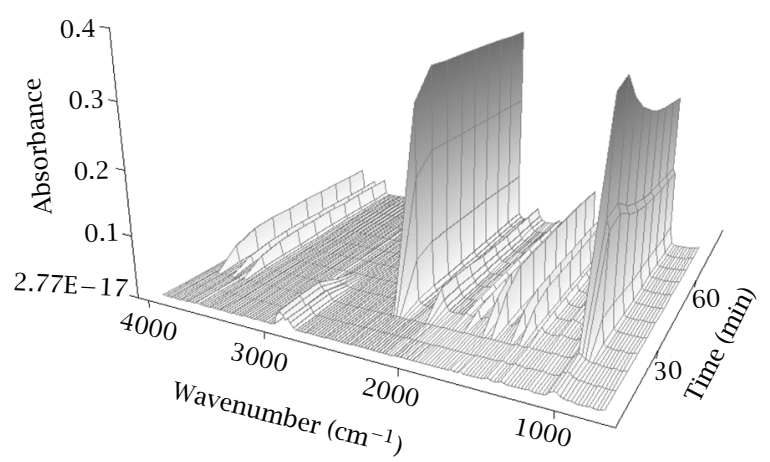

Figure 5. Time evolution of outlet effluent IR spectrum during gas $\mathrm{BuOH}$ photolysis at $172 \mathrm{~nm}$ (total irradiation time: 2 hours).

As shown in Figure 5, the vibrations characteristic band of $\mathrm{C}-\mathrm{H}$ bond $\left(\sim 3000 \mathrm{~cm}^{-1}\right)$, that allowed us to follow the pollutant, disappeared as soon as that the lamp was switched on, indicating that total mineralization of $\mathrm{BuOH}$ was obtained. This irradiation is characterised by the appearance of the ozone band around $1000 \mathrm{~cm}^{-1}$. The mineralization was confirmed by the presence of the $\mathrm{CO}_{2}$ typical band $\left(2350 \mathrm{~cm}^{-1}\right)$ being very large due to its strong molar absorptivityas well as two water characteristic bands in the 1300$2000 \mathrm{~cm}^{-1}$ and $3500-4000 \mathrm{~cm}^{-1}$.

In case of $\mathrm{BuOH}$ irradiation conducted with saturated DAY-zeolite, the $\mathrm{BuOH} \mathrm{C}-\mathrm{H}$ band $\left(3000 \mathrm{~cm}^{-1}\right)$ completely disappeared after one hour of illumination. Here, degradation intermediates like aldehyde (band at $1740 \mathrm{~cm}^{-1}$ ) were detected but not yet identified. They

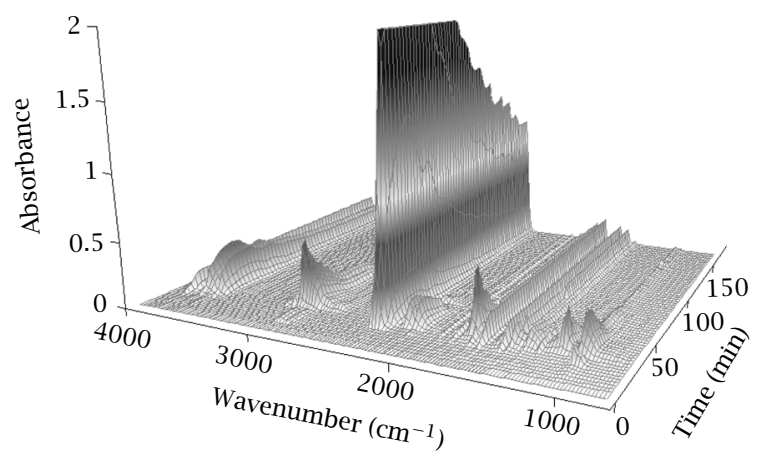

Figure 6. Time evolution of outlet effluent IR spectrum during DAY-zeolites saturated by $\mathrm{BuOH}$ irradiation at $172 \mathrm{~nm}$ (total irradiation time: 2 hours). disappear almost at the same time as $\mathrm{BuOH}$. After one hour of irradiation, the steady-state was reached and the quantities of water corresponded to the mineralization of the on-going $\mathrm{BuOH}$ entering the reactor. Carbon monoxide was also formed during the first hour (bands at $\sim 2150 \mathrm{~cm}^{-1}$ ), indicating that, at the beginning of irradiation, the pollutant concentration was so high that a lack of oxygen occurred. Oxygen presence has been demonstrated to be essential to get total mineralization [24]. Investigations of alternative adsorption/photolysis V-UV phases confirmed that the adsorbent was then totally regenerated. It is interesting to note that in the experiments carried out on a zeolite, the ozone quantity detected remained stable and was smaller compared to the one obtained during direct photolysis. This tend to indicate that the ozone formed is either consumed in gas oxidation of pollutants, or adsorbed on zeolite surface. Ozone was reported to have a high affinity with acid sites of zeolites [37], and its basic character was found to be similar to CO. This phenomenon was observed when irradiating unpolluted zeolite: the ozone formed was first consumed by the zeolite, and then its concentration increased up to its initial value. From this observation, it is clear that the two phenomena mentioned earlier were happening simultaneously.

Very similar results were obtained when irradiating MEK-fully saturated DAY, as presented in Figure 7. MEK is characterised by bands at $1797 \mathrm{~cm}^{-1}$ (ketone), and in the $2700 \mathrm{~cm}^{-1}$ to $3000 \mathrm{~cm}^{-1}$ range $(\mathrm{C}-\mathrm{H})$. These bands disappear totally and water gets to a steady state after one hour of irradiation. At the same time, ozone is also present in very small quantity and CO band is present during the first hour.

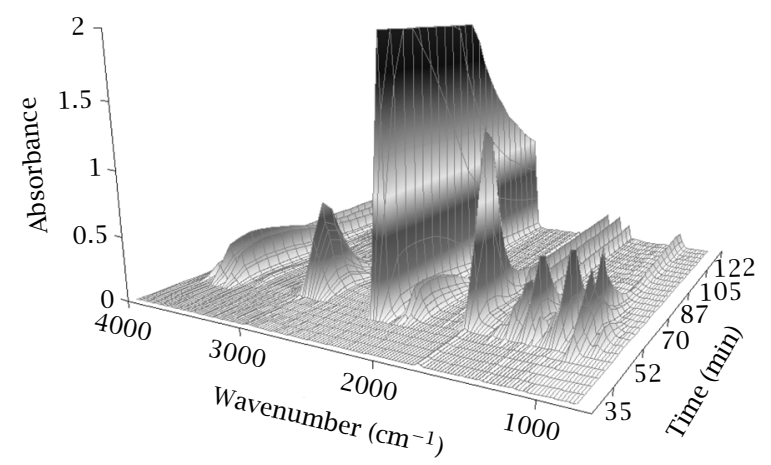

Figure 7. Time evolution of outlet effluent IR spectrum during DAY-zeolites saturated by MEK irradiation at $172 \mathrm{~nm}$. (total irradiation time: 2 hours)

The great efficiency of this technique comes from the combination of several oxidation paths. Firstly, depending on their specific absorbance spectrum, VOC can be directly photolysed at $172 \mathrm{~nm}$. At the same time, photodissociation of dioxygen lead to two single atoms 
of oxygen, which react afterwards with dioxygen and produce ozone [19]. Ozone may then act directly as an oxidative specie but can also be photolysed, in spite of its low absorbance at $172 \mathrm{~nm}$, and produce oxygen atoms at an excited state [38]. Falkenstein's findings confirmed this statement [20], showing that this radical was one of the active species in the degradation of isopropanol by V-UV photolysis.

\section{CONCLUSION}

This study aimed at regenerating zeolite adsorbents using oxidative techniques. Firstly, two zeolites with very different crystalline framework were used as supports for $\mathrm{TiO}_{2}$ impregnation. Physical characterisation of materials showed that a great intimacy of loading was obtained without significant modification of adsorbent. Using these new catalysts in dynamic photocatalysis experiments, it was clarified that the zeolite did not interfere with oxidation mechanism of $\mathrm{BuOH}$, and that intracrystalline diffusion was likely to be the limiting kinetic parameter. In a second approach, V-UV photolysis was used to regenerate commercial zeolite, used here as a pollutant reservoir. Total degradation of pollutants, at relatively high concentrations, and complete and rapid regeneration of adsorbent was obtained, indicating a major influence of ozone.

\section{ACKNOWLEDGEMENTS}

The authors are grateful to the "Conseil Régional de Midi Pyrénées” for financial support of this work, Prof. A. M. Braun for discussions and material support and to Dr. M. T. Boisdon and G. Tayebi for technical support.

\section{REFERENCES}

[1] P. Le Cloirec, Les composés organiques volatils dans l'environnement, Lavoisier Tec. \& Doc., Paris, 1998.

[2] O. Legrini, E. Oliveros, and A. M. Braun, Chem. Rev. 93 (1993), 671.

[3] D. F. Ollis, Photocatalytic Purification and Treatment of Water and Air, Elsevier, Lausanne, 1993.

[4] D. Robert, A. Piscoro, O. Heintz, and J. V. Weber, Catalysis Today 54 (1999), 291.

[5] Y. Zhu, L. Zhang, L. Wang, Y. Fu, and L. Cao, Journal of Material Chemistry 11(7) (2001), 1864.

[6] Y. Ku, C. M. Ma, and Y. S. Shen, Applied Catalysis B: Environmental 34 (2001), 181.

[7] F. Benoit-Marquié, Ph.D. Thesis no. 2632, Université Paul Sabatier, Toulouse, France, 1997.

[8] A. Fernandez, G. Lassaletta, V. M. Jimenez, A. Justo, A. R. Gonzalez-Elipe, J. M. Herrmann, H. Tahiri, and Y. Ait-Ichou, Applied Catalysis B: Environment 7 (1995), 49.
[9] N. Takeda, N. Iwata, T. Torimoto, and H. Yoneyama, Journal of Catalysis 177 (1998), 240.

[10] K. J. Green and R. J. Rudham, Chemical Society, Faraday Trans. 89 (1993), 1867.

[11] S. Brosillon, M.-H. Manero, and J.-N. Foussard, Environmental Science and Technology 35 (2001), 3571.

[12] R. M. Alberici and W. F. Jardim, Applied Catalysis B: Environmental 14 (1997), 55.

[13] K. Hashimoto, K. Wasada, M. Osaki, E. Shono, K. Adachi, N. Toukai, H. Kominami, and Y. Kera, Applied Catalysis B: Environmental 30 (2001), 429.

[14] H. Ichiura, T. Kitaoka, and H. Tanaka, Proceeding on "Environmentally Friendly and Emerging Technologies for a suitable Pulp and Paper Industry", Taiwan, 2000.

[15] Z. Ding, X. Hu, P. L. Yue, G. Q. Lu, and P. F. Greenfield, Catalysis Today 68 (2001), 173.

[16] Y. Kim and M. Yoon, Journal of Molecular Catalysis A: Chemical 168 (2001), 257.

[17] M. G. Kang, H. S. Park, and K.-J. Kim, Journal of Photochemistry and Photobiology A: Chemistry, 2002 (in press).

[18] F. Benoit-Marquié, U. Wilkenhoener, A. M. Braun, E. Oliveros, and M. T. Maurette, J. Phys. IV (France) 9 (1999), 113, and references therein.

[19] A. M. Braun, M. T. Maurette, and E. Oliveros, Photochimie 94, Suppl. Actual. Chim. 7 (1994), 76.

[20] Z. Falkenstein, Ph.D. Thesis, Karlsruhe, Germany, 1996.

[21] C. Bailleux and F. Benoit-Marquié, French Patent FR 0002923 (2001).

[22] P. Monneyron, F. Benoit-Marquié, M.-T. Maurette, M.-H. Manero, and J.-N. Foussard, Air Pollution 2002, Segovia, 1-3 July, 2001 (in press).

[23] J. M. McKelvey and H. E. Hoelscher, Anal. Chem. 29(1) (1957), 123.

[24] F. Benoit-Marquié, M. T. Boisdon, A. M. Braun, E. Oliveros, and M.-T. Maurette, Entropie 228 (2000), 36.

[25] F. Benoit-Marquié, U. Wilkenhöner, V. Simon, A. M. Braun, E. Oliveros, and M.-T. Maurette, J. Photochem. Photobiol. A: Chem. 132 (2000), 225.

[26] L. Jakob, Ph.D. Thesis Ecole Polytechnique Fédérale de Lausanne, 1992.

[27] P. Monneyron, M. H. Manero, J. N. Foussard, F. Benoit-Marquié, M. T. Maurette, Chem. Eng. Sci., 2002 (in press).

[28] IUPAC Phys. Chem. Div., Pure Appl. Chem. 57(4) (1985), 603.

[29] Y.-H. Hsien, C. F. Chang, Y.-H. Chen, and S. Cheng, Applied Catalysis B: Environmental 31 (2001), 241.

[30] R. M. Alberici and W. F. Jardim, Applied Catalysis B: Environmental 14 (1997), 55.

[31] G. B. Raupp and T. C. Junion, Appl. Surf. Sci. 72 (1993), 321. 
[32] S. Sampath, H. Uchida, and H. Yoneyama, Journal of Catalysis 149 (1994), 189.

[33] H. Chen, A. Matsumoto, N. Nishimiya, and K. Tsutsumi, Colloids Surf. A 157 (1999), 295.

[34] T. R. Brueva, I. V. Mishin, and G. I. Kapustin, Thermochimica Acta 379 (2001), 15.

[35] H. Yoneyama and T. Torimoto, Catalysis Today 58 (2000), 133.

[36] V. Keller-Spitzer, P. Bernhardt, G. Maire, and M. J.
Ledoux, 2nd European meeting on solar-chemistry and photocatalysis: environmental applications, Saint Avold France, 2002.

[37] L. Mariey, J. Lamotte, P. Hoggan, J.-C. Lavalley, K. Boulanine, and A. Tsyganenko, Chemistry Letters 8 (1997), 835.

[38] W. H. Glaze, J. W. Kang, and D. H. Chapin, Ozone Sci. Ing. 9 (1987), 335. 


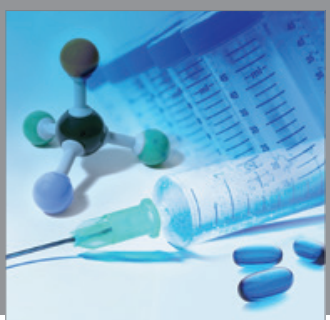

International Journal of

Medicinal Chemistry

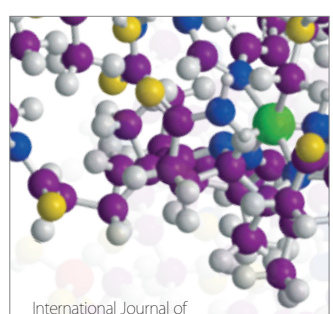

Carbohydrate Chemistry

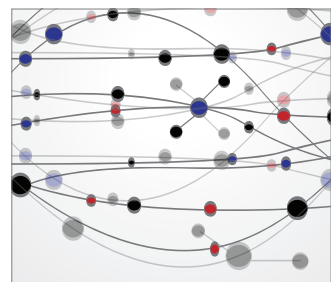

The Scientific World Journal
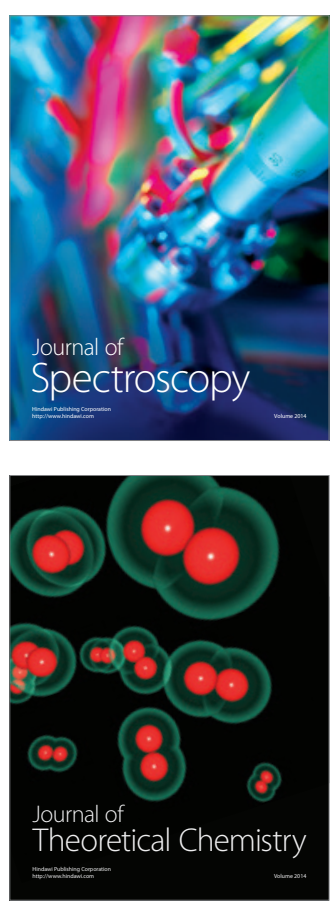
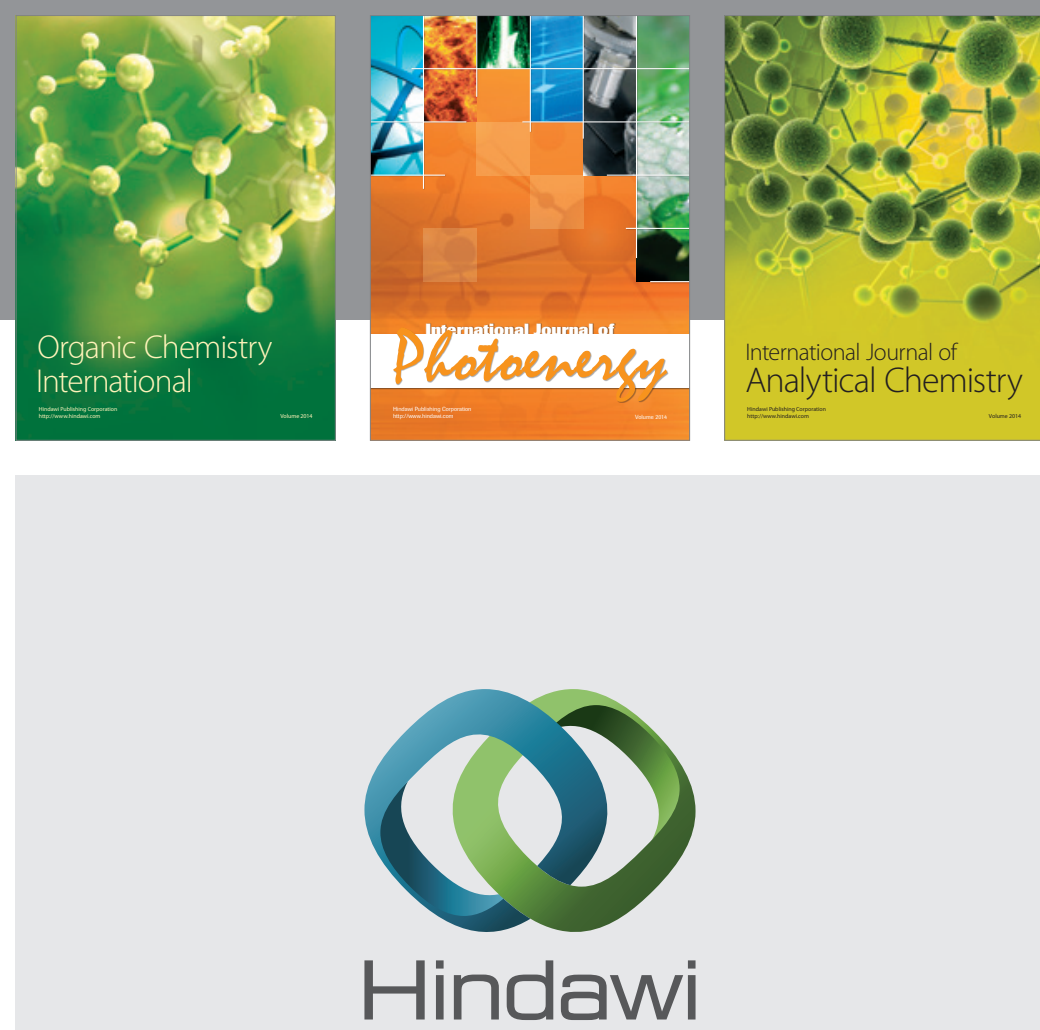

Submit your manuscripts at

http://www.hindawi.com
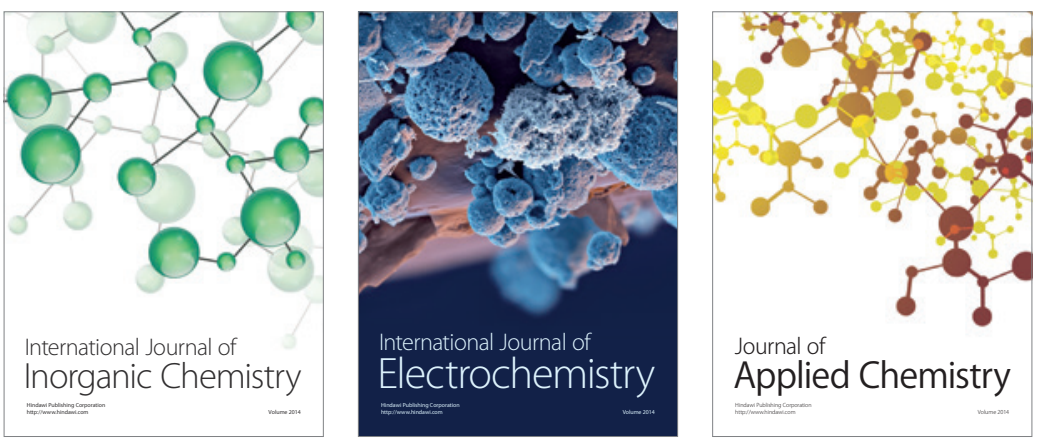

Journal of

Applied Chemistry
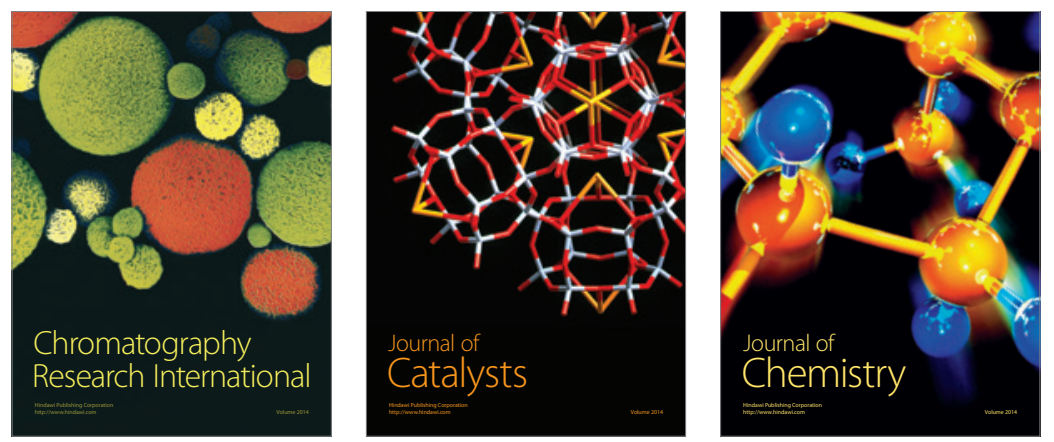
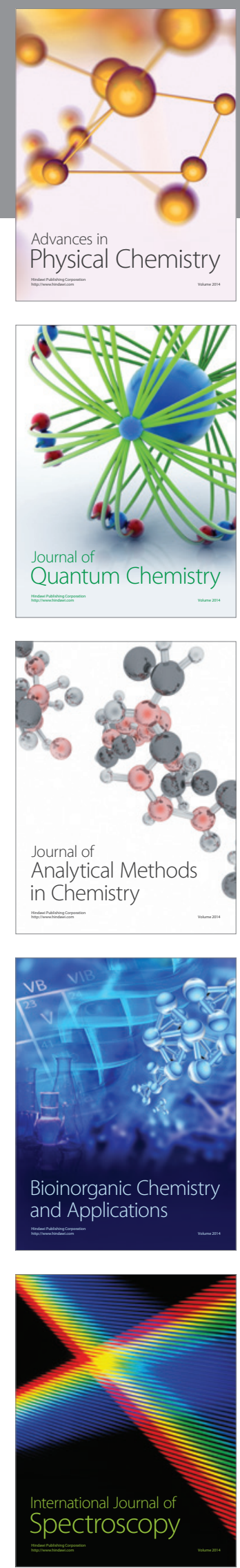